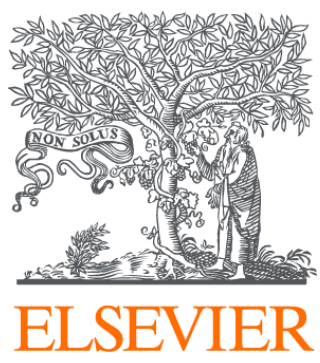

Since January 2020 Elsevier has created a COVID-19 resource centre with free information in English and Mandarin on the novel coronavirus COVID-

19. The COVID-19 resource centre is hosted on Elsevier Connect, the company's public news and information website.

Elsevier hereby grants permission to make all its COVID-19-related research that is available on the COVID-19 resource centre - including this research content - immediately available in PubMed Central and other publicly funded repositories, such as the WHO COVID database with rights for unrestricted research re-use and analyses in any form or by any means with acknowledgement of the original source. These permissions are granted for free by Elsevier for as long as the COVID-19 resource centre remains active. 
katharina.lauer@postgrad.manchester. ac.uk

University of Manchester, Manchester M13 9PT, UK (KBL, LF, TJB); and North Manchester General Hospital, Manchester, UK (TJB)

1 Tully CM, Lambe T, Gilbert SC, Hill AVS. Emergency Ebola response: a new approach to the rapid design and development of vaccines against emerging diseases. Lancet Infect Dis 2015; 15: 359-9.

2 Sullivan N, Yang Z, Nabel GJ. Ebola virus pathogenesis: implications for vaccines and therapies. Jirol 2003; 77: 9733-37.

3 Wong G, Kobinger GP, Qiu X. Characterization of host immune responses in Ebola virus infections. Expert Rev Clin Immunol 2014; 10: 781-90

4 Baize S, Leroy EM, Georges-Courbot MC, et al. Defective humoral responses and extensive intravascular apoptosis are associated with fatal outcome in Ebola virus-infected patients. Nat Med 1999; 5: 423-26.

5 Parren PW, Geisbert TW, Maruyama T, Jahrling PB, Burton DR. Pre- and postexposure prophylaxis of Ebola virus infection in an anima model by passive transfer of a neutralizing human antibody. JVirol 2002; 76: 6408-12.

6 Shedlock DJ, Aviles J, Talbott KT, et al. Induction of broad cytotoxic T cells by protective DNA vaccination against Marburg and Ebola. Mol Ther 2013; 21: 1432-44.

\section{Ebola superspreading}

Ousmane Faye and colleagues ${ }^{1}$ recently described the chains of transmission for 152 individuals infected with Ebola virus diseases in Guinea. The resulting transmission trees provide unique insights into the individual variation in the number of secondary cases generated by an infected index case. A better understanding of this variation provides crucial information about epidemic spread, the expected number of superspreading events, and the effects of control measures. ${ }^{2}$

The number of secondary cases in the transmission trees is highly skewed, with $72 \%$ of individuals not generating further cases (figure). Fitting a negative binomial distribution to the data (appendix) provides maximumlikelihood estimates of the mean (0.95, 95\% Cl 0.57-1.34) and the dispersion parameter $(k=0.18,95 \% \mathrm{Cl} 0 \cdot 10-0 \cdot 26)$. The mean corresponds to the basic reproduction number $\left(R_{0}\right)$ of the overall population. The estimated value of $k$, which is substantially smaller than 1 , suggests that the distribution of the individual reproduction number is highly overdispersed. ${ }^{2}$ The value for Ebola virus disease is similar to that estimated for severe acute respiratory syndrome $(k=0 \cdot 16) .^{2}$ This finding suggests that superspreading events for Ebola virus disease are an expected feature of the individual variation in infectiousness. ${ }^{3}$

I simulated stochastic trajectories of Ebola virus disease outbreaks starting from one infected index case (figure). To this end, I drew the number of secondary cases for each case from the fitted negative binomial distribution (appendix). The time from disease onset in one case to disease onset in the next case was drawn from the reported gamma-distributed serial interval with a mean duration of $15 \cdot 3$ days. ${ }^{4}$ Although most outbreaks rapidly become extinct, some epidemic trajectories can reach to more than 100 infected cases. This finding is particularly remarkable because $R_{0}$ is less than 1 , and shows the potential for explosive outbreaks of Ebola virus disease.

$R_{0}$ during the early phase of the Ebola virus disease epidemic in Guinea has been estimated to be roughly $1.5 .^{5}$ The transmission trees from Faye and colleagues were generated from data obtained between February and August, 2014, when the reproduction number was fluctuating around unity. ${ }^{1,4}$ That scenario is similar to the present situation in parts of west Africa where the incidence is declining but new outbreaks still occur. The observed variation in individual infectiousness for Ebola virus disease means that although the probability of extinction is high, new index cases also have the potential for explosive regrowth of the epidemic.

I received funding through an Ambizione grant from the Swiss National Science Foundation (project 136737). I declare no competing interests.

\section{Christian L Althaus}

christian.althaus@alumni.ethz.ch

Institute of Social and Preventive Medicine, University of Bern, 3012 Bern, Switzerland

1 Faye O, Boëlle P-Y, Heleze E, et al. Chains of transmission and control of Ebola virus disease in Conakry, Guinea, in 2014: an observational study. Lancet Infect Dis 2015; 15: 320-26.
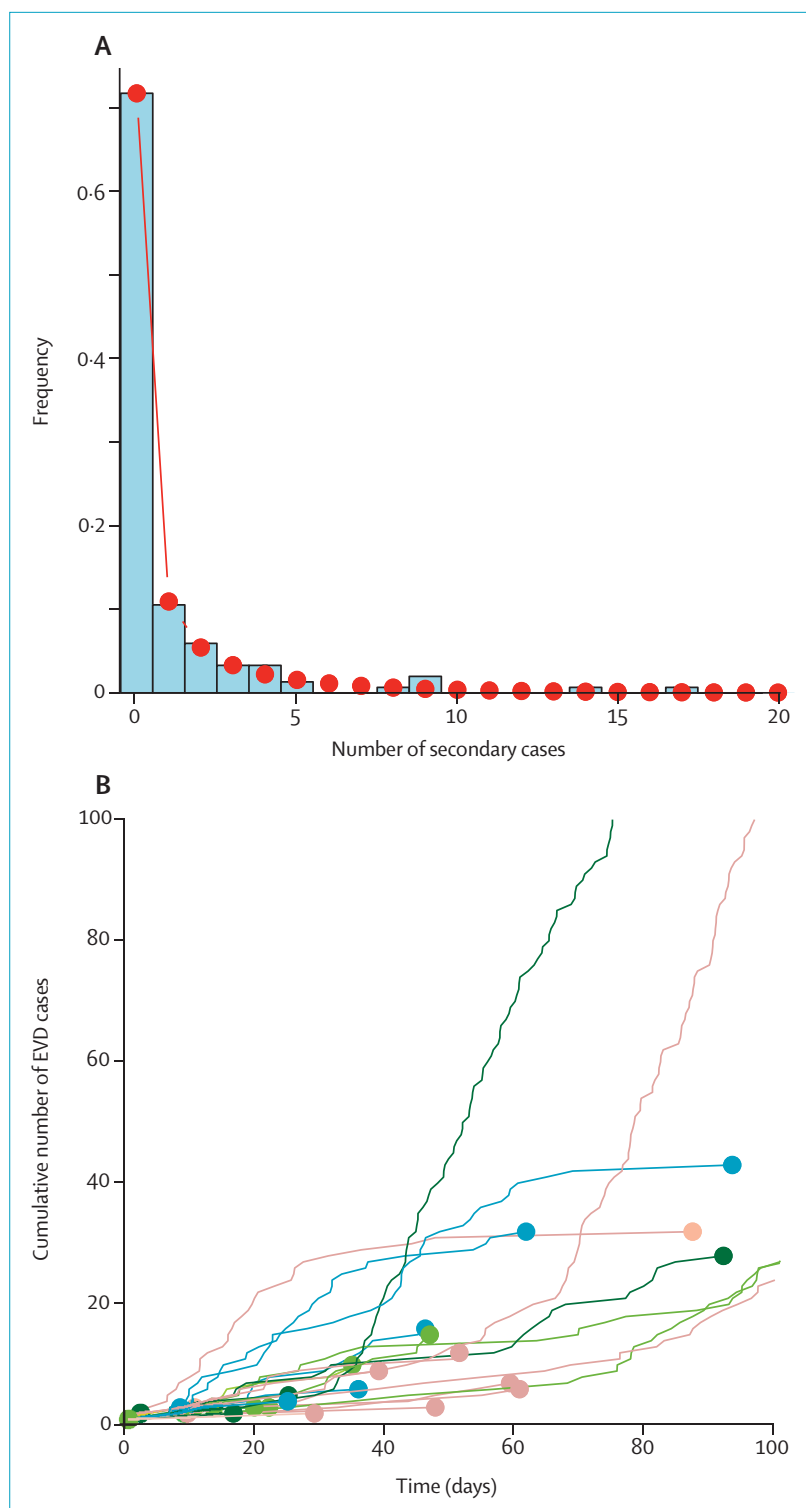

Figure: Distribution of the number of secondary cases and outbreak trajectories for Ebola virus disease

(A) The histogram represents the observed frequencies in the number of secondary cases as given by the transmission trees in Faye and colleagues' study. ${ }^{1}$ The line and dots correspond to the fitted negative binomial distribution. (B) Each line represents one of 200 stochastic realisations of epidemic trajectories. Dots show when the outbreak becomes extinct. A detailed analysis is reported in the appendix. EVD=Ebola virus disease.

2 Lloyd-Smith JO, Schreiber SJ, Kopp ME, Getz WM. Superspreading and the effect of individual variation on disease emergence. Nature 2005; 438: 355-59.

3 Volz EM, Pond SL. Phylodynamic analysis of Ebola virus in the 2014 Sierra Leone epidemic. PLoS Curr 2014; published online Oct 24. DOI:10.1371/currents.outbreaks.6f7025f1271 $821 \mathrm{~d} 4 \mathrm{c} 815385 \mathrm{~b} 08 \mathrm{f} 5 \mathrm{f} 80 \mathrm{e}$

4 WHO Ebola Response Team. Ebola virus disease in West Africa-the first 9 months of the epidemic and forward projections. N EnglJ Med 2014; 317: 1481-95.

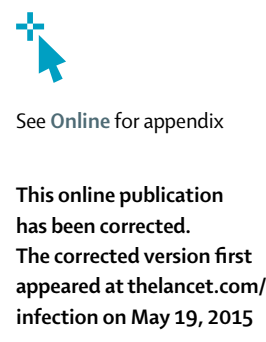

infection on May 19, 2015 
5 Althaus CL. Estimating the reproduction number of Ebola virus (EBOV) during the 2014 outbreak in West Africa. PLoS Curr 2014; published online Sept 2. DOI:10.1371/ currents.outbreaks.91afb5e0f279e7f29e7056 $095255 b 288$.

\section{Norovirus in patients with gastroenteritis}

In a comprehensive and updated systematic review and meta-analysis, Sharia Ahmed and colleagues ${ }^{1}$ assessed the role of norovirus as a cause of endemic acute gastroenteritis worldwide. In their pooled analysis of 175 studies, noroviruses were detected in $18 \%$ of patients with acute gastroenteritis: $24 \%$ in the community, $20 \%$ in outpatients, and $17 \%$ in inpatients. ${ }^{1}$

Identification of the causal role of noroviruses in acute gastroenteritis is very important, in view of the possibility of shifting patterns of causal agents of acute gastroenteritis in some regions, characterised by a decreasing proportion of bacterial enteropathogens and the emergent role of enteric viruses. ${ }^{2}$ We do not know whether the introduction of rotavirus immunisation in many regions, with a subsequent substantial reduction in cases of rotavirus diarrhoea, ${ }^{3}$ will lead to the replacement of rotavirus by other agents (eg, norovirus) as the leading cause of paediatric diarrhoea. Thus, findings such as those reported by Ahmed and colleagues ${ }^{1}$ are valuable for the monitoring of changes in the cause of diarrhoeal diseases and to set public health priorities.

Nonetheless, norovirus is detected in high proportions of asymptomatic people, as a result of truly asymptomatic infections or shedding after a gastroenteritis episode. ${ }^{4}$ Furthermore, in children residing in developing countries, mixed enteric infections are very common in both sick and healthy people. Therefore, because the assessment by Ahmed and colleagues ${ }^{1}$ did not account for the background level of norovirus infection-ie, in patients without diarrhoea-and the presence of other enteric pathogens in the same stool specimen, it might have overestimated the causal role of norovirus in endemic gastroenteritis.

Last, norovirus genotypes might vary between endemic and epidemic gastroenteritis. All norovirus outbreaks in adults in Israel between 2003 and 2014 were caused by genotype GII.4. Sporadic cases in adults were under-reported. Outbreaks in adults were almost exclusively associated with closed settings (eg, old age or extended care facilities) and norovirus-positive cases were diagnosed in patients, staff, and, in some cases, families of staff. By contrast, endemic cases in children younger than 5 years admitted to hospital ${ }^{5}$ included six genotypes in addition to Gll.4. This genotypedependent and age-dependent epidemiological difference and underdiagnosis and under-reporting of sporadic adult cases of norovirus gastroenteritis would also affect the burden estimates of norovirus illness.

We declare no competing interests.

\section{*Khitam Muhsen, Lester Shulman, Dani Cohen}

\section{kmuhsen@post.tau.ac.il}

Department of Epidemiology and Preventive Medicine, School of Public Health, Sackler Faculty of Medicine, Tel Aviv University, Tel Aviv 6139001, Israel (KM, LS, DC); and Reference Virology Laboratory, Ministry of Health, Sheba Medical Center, Tal Hashomer, Isreal (LS)

1 Ahmed SM, Hall AJ, Robinson AE, et al. Global prevalence of norovirus in cases of gastroenteritis: a systematic review and meta-analysis. Lancet Infect Dis 2014 14: 725-30.
2 Podewils LJ, Mintz ED, Nataro JP, Parashar UD Acute, infectious diarrhea among children in developing countries. Semin Pediatr Infect Dis 2004; 15: 155-68.

3 Patel MM, Glass R, Desai R, Tate JE, Parashar UD. Fulfilling the promise of rotavirus vaccines: how far have we come since licensure? Lancet Infect Dis 2012; 12: 561-70.

4 Glass RI, Parashar UD, Estes MK. Norovirus gastroenteritis. N EnglJ Med 2009; 361: 1776-85.

5 Muhsen K, Kassem E, Rubinstein U, et al. Incidence and characteristics of sporadic norovirus gastroenteritis associated with hospitalization of children less than 5 years of age in Israel. Pediatr Infect Dis J 2013; 32: 688-90.

\section{Bacterial meningitis in the USA}

We read with great interest the Article by Rodrigo Lopez Castelblanco and colleagues $^{1}$ about bacterial meningitis in the USA. The authors do a commendable job assessing the Nationwide Inpatient Sample, the largest nationally representative dataset of all-payer (which includes data from both private and public payers of health care) patient hospital discharges in the USA, to provide estimates for the number of admissions to hospital attributed to bacterial meningitis in the USA. Castelblanco and colleagues ${ }^{1}$ showed that introduction of conjugated vaccines was associated with a decrease in incidence and mortality due to Streptococcus pneumoniae meningitis and introduction of recommendations to use adjunctive dexamethasone was associated with a reduction in mortality due to pneumococcal

\begin{tabular}{|c|c|c|c|c|c|c|c|}
\hline & 2006 & 2007 & 2008 & 2009 & 2010 & 2011 & Total (2006-11) \\
\hline 320.0 (haemophilus meningitis) & 187 & 217 & 243 & 182 & 244 & 267 & 1340 \\
\hline $320 \cdot 1$ (pneumococcal meningitis) & 1320 & 1297 & 1301 & 1192 & 1052 & 1106 & 7268 \\
\hline $320 \cdot 3$ (staphylococcus meningitis) & 1267 & 1146 & 1148 & 995 & 1195 & 1296 & 7047 \\
\hline $\begin{array}{l}320 \cdot 82 \text { (meningitis due to } \\
\text { Gram-negative bacteria) }\end{array}$ & 960 & 864 & 991 & 820 & 987 & 905 & 5527 \\
\hline \multicolumn{8}{|c|}{$\begin{array}{l}\text { International Classification of Diseases } 9 \text { (ICD-9) coding is used to classify different types of meningitis. Data are } \\
\text { from the US Agency for Healthcare Research and Quality HCUPnet. }{ }^{2}\end{array}$} \\
\hline $\begin{array}{l}\text { Table: Number of hospital emergen } \\
2006-11 \text {, by ICD- } 9 \text { code }\end{array}$ & cy dep & tmen & ISITS & o bac & rial me & eningit & is in the USA, \\
\hline
\end{tabular}

